DOI : 10.12816/amj.2020.91612

https://amj.journals.ekb.eg/article_91612.html

\title{
DIFFERENT REGIMENS OF MAGNESIUM SULFATE FOR MANAGEMENT OF WOMEN WITH SEVERE PREECLAMPSIA
}

\author{
By \\ Mostafa A. Hekal ,Yehia A. Wafa, and Mohammed I. El-Mohandes \\ Department of Obstetrician and Gynecologist, Faculty of Medicine, Al-Azhar University, \\ Corresponding author: Mostafa Hekal, Mobile: 01121909264, \\ E-mail: doctorhekal@gmail.com
}

\begin{abstract}
Background: Preeclampsia is serious syndrome that can affect human pregnancy causing serious complications. Preeclampsia is pregnancy-specific syndrome of reduced organ perfusion secondary to vasospasm and endothelial activation.

Objective: To assess the comparative effects of three regimens for the administration of the magnesium sulfate when used for the care of women with severe preeclampsia to determine the minimal effective dose of magnesium sulfate in controlling cases with severe preeclampsia and prevention of eclampsia and to determine whether only loading dose of magnesium sulfate is effective in prevention of eclampsia or not.
\end{abstract}

Patients and Methods: 240 patients were recruited and divided into three groups. Each group contains 80 patients, the first group received only the loading dose of $\mathrm{MgSO} 4$ and the second group received loading dose plus 12 hours maintenance dose while the last group received the loading dose and the full maintenance dose of $\mathrm{MgSo} 4$ for 24 hours.

Results: Although strong evidence supports the use of magnesium sulfate for prevention and treatment of eclampsia, there was no significant difference between occurrence of eclampsia in the three groups after either administration of loading dose of $\mathrm{MgSO} 4$ only or administration of loading dose with maintenance dose for 12 hours or maintenance dose for 24 hours in the studied patients.

Conclusion: Magnesium sulfate proved to cause many hemodynamic changes as it has vasodilator effect on maternal and fetal blood vessels; however, magnesium sulfate should be given to all patients with severe preeclampsia.

Key words: Magnesium sulfate, management, severe preeclampsia.

\section{INTRODUCTION}

Preeclampsia is a multisystem disorder of pregnancy which is a major cause of maternal and fetal morbidity and mortality worldwide. The cardinal clinical features of the condition are hypertension and proteinuria occurring after 20 weeks gestation in women who were not previously known to be hypertensive (Uzan et al., 2011).
Pre-eclampsia often affects young and nulliparous women, whereas older women are at great risk of chronic hypertension with superimposed preeclampsia (Young et al., 2010).

Preeclampsia is considered severe if one or more of the following:, Blood pressure of $160 \mathrm{mmHg}$ systolic or higher or $110 \mathrm{mmHg}$ diastolic or higher on two 
occasions at least 6 hours a part while the patient on bed rest., Proteinuria of $3 \mathrm{gm}$. in 24 hours urine specimen or $+2>$ on two random urine samples collected at least 4 hours apart., Oliguria of less than $500 \mathrm{ml}$ in 24 hours., Cerebral or visual disturbance, pulmonary edema or cyanosis., epigastric or right upper quadrant pain., Impaired liver function., thrombocytopenia., Fetal growth restriction (Al-Jameil et al., 2014).

In normal pregnancy the spiral arteries in the placental bed are invaded by trophoblast, which becomes incorporated into the vessel wall and replaces the endothelium, muscular layer and neural tissue. These physiological changes convert the spiral arteries from narrow muscular vessels to wide non-muscular channels independent of maternal vasomotor control. Pre-eclampsia is thought to be the consequence of impaired trophoblastic invasion of the maternal spiral arteries (Cui et al., 2012).

Magnesium sulfate is widely used in obstetrics and is a drug of choice in two important complications of pregnancy, preeclampsia and preterm labor. Magnesium sulfate is used to prevent seizures in preeclampsia patients (Smith et al., 2013).

The most common side effect is flushing. Others are far less common and include nausea, vomiting, muscle weakness, thirst, headache, drowsiness and confusion. Although magnesium sulfate can lead to respiratory depression and respiratory arrest, these hazards appear to be rare. Higher dose regimens may be associated with a great risk of side effects and adverse effects. If magnesium sulfate toxicity does occur, intravenous calcium gluconate is an effective antidote (Duley et al., 2010).

Magnesium sulfate remains the drug of choice for both prevention and treatment of women with eclampsia. Regimens for administration of this drug have evolved over the years, but have not yet been formally evaluated (Dhakal et al., 2012).

In past, MgSO4 was given according to Pritchard regime in which 5 grams of magnesium sulfate was administered fourhourly for 24 hours after loading with 14 grams. It was observed that many patients did not receive maintenance therapy due to suspicion of toxicity but they did not convulse any further. On the basis of this observation, many studies were planned to compare the efficacy of loading dose of magnesium sulfate versus the standard regime in the management of preeclampsia to prevent fits.

Implementation of magnesium sulfate would be strengthened if guidelines and recommendations for practice could be based on reliable evidence about the comparative effects of alternative regimens. It is therefore relevant to assess the pros and cons of alternative strategies for administration. As administration of magnesium sulfate requires regular supervision by trained staff, which is costly, and higher doses may be associated with a greater risk of side effects and adverse events, it is particularly important to assess the minimum effect dose and duration of treatment (Greenberg et al., 2013).

In our study we will try to assess the comparative effects of three regimens for the administration of magnesium sulfate when used for the care of women with severe pre-eclampsia. 
The aim of the study was to assess the comparative effects of three regimens for the administration of the magnesium sulfate when used for the care of women with severe preeclampsia to determine the minimal effective dose of magnesium sulfate in controlling cases with severe preeclampsia and prevention of eclampsia and to determine whether only loading dose of magnesium sulfate is effective in prevention of eclampsia or not.

\section{PATIENTS AND METHODS}

The study is prospective randomized comparative study that compares three regimens for administration of $\mathrm{MgSO} 4$ used for the cases of severe pre-eclampsia that were performed in Al-Galaa Maternity Teaching Hospital.

The study included 240 pregnant women presenting to the casualty unit diagnosed as a case of preeclampsia with criteria of severity in the form of the following:

Systolic blood pressure > 160., Diastolic blood pressure >110., Proteinuria $>+2$ by dip stick ( $3 \mathrm{gm} / 24$ hrs)., Presence of alarming symptoms (headache, visual disturbance, epigastric pain, vaginal bleeding).

The study included pregnant1 females $>37$ weeks living fetus, pregnant females with criteria of severe pre-eclampsia, single pregnancy and primigravida.

While pregnant females with history of epilepsy, medical disorders: pregnant females with mild preeclampsia, pregnant females with eclampsia and superimposed patients will be excluded from the study.

After obtaining an informed consent the patients were subjected to the following: Careful history taking including age, parity, gestational age. Complete physical examination and assessment of the blood pressure. Urine analysis by dipstick. Blood sample was taken from the patient for laboratory investigations in the form of $\mathrm{CBC}$, coagulation profile, liver function tests and kidney function tests. Ultrasound was done for each patient for assessment of fetal wellbeing, liquor and placenta.

In All groups, women took initial loading dose $\mathrm{MgSO} 4$ (6 grams of $\mathrm{MgSO} 4$ on $250 \mathrm{ml}$ ringer solutions over 20 minutes by IV drip).

Using Random Number Table, the sample was divided into three categories:

- Category A - 80 patients who took only loading dose of $\mathrm{MgSO} 4$ (6 grams of $\mathrm{MgSO} 4$ on $250 \mathrm{~m} 1$ ringer solutions over 20 minutes) with no postpartum maintenance sulfate.

- Category B ->80 patients given after initial loading dose, abbreviated doses of $\mathrm{MgSO}_{4}$ (4 grams of $\mathrm{MgSO} 4$ on 250 $\mathrm{ml}$ ringer solution over 4 hours every 4 hours by IV drip only for 12 hours) in the postpartum period.

- Category - C 80 patients given after initial loading dose, full dose of maintenance $\mathrm{MgSO} 4$ (4 grams of $\mathrm{MgSO} 4$ on $250 \mathrm{ml}$ ringer solution over 4 hours every 4 hours by IV drip for 24 hours) in the postpartum period.

\section{Technique of Blood Pressure Measurement:}

For the measurement of maternal blood pressure, a mercury sphygmomanometer was used, with a cuff of $20 \times 60 \mathrm{~cm}$. 
- The initial measurement for the diagnosis of severe preeclampsia was performed while the patient being seated, holding her right arm at heart level, being considered the last value obtained.

- After loading dose of magnesium sulfate, new blood pressure measurement was performed. Diastolic pressure was determined by Korotkoff phase V. All measurements were performed by the same researcher.

\section{Statistical analysis:}

Data were statistically described in terms of mean \pm standard deviation $( \pm$
SD), median and range, or frequencies (number of cases) and percentages when appropriate. Comparison of numerical variables between the study groups was done using one way analysis of variance (ANOVA) test. For comparing categorical data, Chi square (x3) test was performed. Exact test was used instead when the expected frequency is less than 5. p values less than 0.05 was considered statistically significant. All statistical calculations were done using computer program SPSS (Statistical Package for the Social Science; SPSS Inc., Chicago, IL, USA) release 15 for Microsoft Windows.

\section{RESULTS}

Mean age of patients was; 26.65 years, SD 5.113 (range; 16-42). Mean gestational age was; 38.88 weeks, SD 2.769 (range; 38-40). Mean systolic BP was; $161.88 \mathrm{mmHg}$, SD 17.121 (range; 100-210). Mean diastolic BP was; 103.15, SD 12.127 (range; 50-120) (Table 1). 
Table (1): Demographic features of the studied patients

\begin{tabular}{|c|c|c|c|c|c|}
\hline \multicolumn{2}{|c|}{\begin{tabular}{|ll} 
Groups & Parameters \\
\end{tabular}} & Age & GA & SBP & DBP \\
\hline \multirow{6}{*}{ A } & Mean & 26.75 & 38.88 & 162.00 & 104.13 \\
\hline & $\mathrm{N}$ & 80 & 80 & 80 & 80 \\
\hline & $\begin{array}{l}\text { Std. Deviation } \\
\end{array}$ & 5.262 & 1.91 & 19.448 & 11.550 \\
\hline & Minimum & 17 & 37 & 100 & 60 \\
\hline & Maximum & 40 & 40 & 210 & 120 \\
\hline & Median & 28.00 & 39 & 160.00 & 110.00 \\
\hline \multirow{6}{*}{ B } & Mean & 26.56 & 38.21 & 162.50 & 105.06 \\
\hline & $\mathrm{N}$ & 80 & 80 & 80 & 80 \\
\hline & Std. Deviation & 4.986 & 1.96 & 14.884 & 10.296 \\
\hline & Minimum & 18 & 37 & 120 & 80 \\
\hline & Maximum & 42 & 40 & 200 & 120 \\
\hline & Median & 27.00 & 38 & 160.00 & 110.00 \\
\hline \multirow{6}{*}{$\mathrm{C}$} & Mean & 26.64 & 38.24 & 161.13 & 100.25 \\
\hline & $\mathrm{N}$ & 80 & 80 & 80 & 80 \\
\hline & Std. Deviation & 5.151 & 1.80 & 16.913 & 13.869 \\
\hline & Minimum & 16 & 37 & 110 & 50 \\
\hline & Maximum & 39 & 40 & 200 & 120 \\
\hline & Median & 28.00 & 38 & 160.00 & 100.00 \\
\hline \multirow{7}{*}{ Total } & Mean & 26.65 & 38.71 & 161.88 & 103.15 \\
\hline & $\mathrm{N}$ & 240 & 80 & 240 & 240 \\
\hline & \begin{tabular}{|l|} 
Std. Deviation \\
\end{tabular} & 5.113 & 1.86 & 17.121 & 12.127 \\
\hline & Minimum & 16 & 37 & 100 & 50 \\
\hline & Maximum & 42 & 40 & 210 & 120 \\
\hline & Median & 28.00 & 39 & 160.00 & 110.00 \\
\hline & $\mathrm{P}$ value & .973 & .761 & .877 & $.028 *$ \\
\hline
\end{tabular}

As regarding parity, mode of delivery difference within the studied groups and proteinuria there were no significant (Table 2).

Table (1): Parity, mode of delivery and proteinuria of the studied patients

\begin{tabular}{|c|c|c|c|c|c|c|c|}
\hline \multicolumn{2}{|c|}{$\begin{array}{ll}\text { Parameters } & \text { Groups } \\
\end{array}$} & & $\mathbf{A}$ & B & $\mathbf{C}$ & Total & $\begin{array}{c}\mathbf{P} \\
\text { value }\end{array}$ \\
\hline \multirow{4}{*}{ Parity } & \multirow{2}{*}{ Multigravida } & Count & 50 & 50 & 51 & 151 & \multirow{4}{*}{0.98} \\
\hline & & $\%$ within Group & $62.5 \%$ & $62.5 \%$ & $63.8 \%$ & $62.9 \%$ & \\
\hline & \multirow{2}{*}{ Primigravida } & Count & 30 & 30 & 29 & 89 & \\
\hline & & $\%$ within Group & $37.5 \%$ & $37.5 \%$ & $36.3 \%$ & $37.1 \%$ & \\
\hline \multirow{4}{*}{ MOD } & \multirow{2}{*}{$\mathrm{CS}$} & Count & 35 & 43 & 45 & 123 & \multirow{4}{*}{0.24} \\
\hline & & $\%$ within Group & $43.8 \%$ & $53.8 \%$ & $56.3 \%$ & $51.3 \%$ & \\
\hline & \multirow{2}{*}{ VD } & Count & 45 & 37 & 35 & 117 & \\
\hline & & $\%$ within Group & $56.3 \%$ & $46.3 \%$ & $43.8 \%$ & $48.8 \%$ & \\
\hline \multirow{6}{*}{ Protein uria } & \multirow{2}{*}{+2} & Count & 1 & 2 & 0 & 3 & \multirow{6}{*}{0.60} \\
\hline & & $\%$ within Group & $1.3 \%$ & $2.5 \%$ & $0.0 \%$ & $1.3 \%$ & \\
\hline & \multirow{2}{*}{+3} & Count & 46 & 50 & 51 & 147 & \\
\hline & & $\%$ within Group & $57.5 \%$ & $62.5 \%$ & $63.8 \%$ & $61.3 \%$ & \\
\hline & \multirow{2}{*}{+4} & Count & 33 & 28 & 29 & 90 & \\
\hline & & $\%$ within Group & $41.3 \%$ & $35.0 \%$ & $36.3 \%$ & $37.5 \%$ & \\
\hline
\end{tabular}

There was no significant difference between occurrence of eclampsia occurrence of HELLP syndrome, maternal side effects and maternal ICU admission in the three groups after either administration of loading dose of $\mathrm{MgSO} 4$ 
only or administration of loading dose with maintenance dose for 12 hours or 24 hours in the studied patients where group
C showing the highest rate for ICU admission while group A showing the lowest rate for ICU admission (Table 3).

Table (2): Comparison between occurrence of eclampsia, HELLP, maternal side effects and maternal ICU admission after administration of MgSO4 in the studied patients

\begin{tabular}{|c|c|c|c|c|c|c|}
\hline \multicolumn{2}{|c|}{$\begin{array}{ll}\text { Groups } \\
\text { Parameters }\end{array}$} & & $\mathbf{A}$ & B & $\mathbf{C}$ & Total \\
\hline \multirow[t]{4}{*}{ Eclampsia } & No & Count & 80 & 79 & 80 & 239 \\
\hline & & $\%$ within Group & $100.0 \%$ & $98.8 \%$ & $100.0 \%$ & $99.6 \%$ \\
\hline & Yes & Count & 0 & 1 & 0 & 1 \\
\hline & & $\%$ within Group & $0.0 \%$ & $1.3 \%$ & $0.0 \%$ & $0.4 \%$ \\
\hline \multirow[t]{2}{*}{ Total } & & Count & 80 & 80 & 80 & 240 \\
\hline & & $\%$ within Group & $100.0 \%$ & $100.0 \%$ & $100.0 \%$ & $100.0 \%$ \\
\hline \multirow{4}{*}{ HELLP } & \multirow{2}{*}{ No } & Count & 78 & 77 & 75 & 230 \\
\hline & & $\%$ within Group & $97.5 \%$ & $96.3 \%$ & $93.8 \%$ & $95.8 \%$ \\
\hline & \multirow{2}{*}{ Yes } & Count & 2 & 3 & 5 & 10 \\
\hline & & $\%$ within Group & $2.5 \%$ & $3.8 \%$ & $6.3 \%$ & $4.2 \%$ \\
\hline \multirow{2}{*}{\multicolumn{2}{|c|}{ Total }} & Count & 80 & 80 & 80 & 240 \\
\hline & & $\%$ within Group & $100.0 \%$ & $100.0 \%$ & $100.0 \%$ & $100.0 \%$ \\
\hline \multirow{4}{*}{$\begin{array}{l}\text { Maternal } \\
\text { Side } \\
\text { effect }\end{array}$} & \multirow{2}{*}{ Flushing } & Count & 8 & 5 & 11 & 24 \\
\hline & & $\%$ within Group & $10.0 \%$ & $6.25 \%$ & $13.8 \%$ & $10 \%$ \\
\hline & \multirow{2}{*}{ No } & Count & 72 & 75 & 69 & 216 \\
\hline & & $\%$ within Group & $90.0 \%$ & $93.75 \%$ & $86.3 \%$ & $90 \%$ \\
\hline \multirow{2}{*}{\multicolumn{2}{|c|}{ Total }} & Count & 80 & 80 & 80 & 240 \\
\hline & & $\%$ within Group & $100.0 \%$ & $100.0 \%$ & $100.0 \%$ & $100.0 \%$ \\
\hline \multirow{4}{*}{ MICU } & \multirow{2}{*}{ No } & Count & 73 & 66 & 50 & 189 \\
\hline & & $\%$ within Group & $91.3 \%$ & $82.5 \%$ & $62.5 \%$ & $78.8 \%$ \\
\hline & \multirow{2}{*}{ Yes } & Count & 7 & 14 & 30 & 51 \\
\hline & & $\%$ within Group & $8.8 \%$ & $17.5 \%$ & $37.5 \%$ & $21.3 \%$ \\
\hline \multirow{2}{*}{\multicolumn{2}{|c|}{ Total }} & Count & 80 & 80 & 80 & 240 \\
\hline & & $\%$ within Group & $100.0 \%$ & $100.0 \%$ & $100.0 \%$ & $100.0 \%$ \\
\hline
\end{tabular}

In more detailed analysis of the significant difference between groups, we found that maternal ICU admission was significant between Group A and Group $\mathrm{C}$, and non-significant between Group A
\& B as Group A showed the lowest percentage in maternal ICU admission while Group $\mathrm{C}$ shows the highest maternal ICU admission with $\mathrm{P}$ value less than 0.0001 (Table 4).

Table (3): Comparison between maternal ICU admission in the group A vs group B, group B vs group $C$ and group $A$ vs group $C$ after administration of MgSO4

\begin{tabular}{|c|c|c|c|c|c|c|c|c|c|c|c|}
\hline \multicolumn{3}{|c|}{$\begin{array}{ll}\text { Parameters } & \text { Groups } \\
\end{array}$} & $\mathbf{A}$ & B & Total & B & C & Total & $\mathbf{A}$ & $\mathbf{C}$ & \\
\hline \multirow{4}{*}{ MICU } & \multirow[b]{2}{*}{ No } & Count & 73 & 66 & 139 & 66 & 50 & 116 & 73 & 50 & 123 \\
\hline & & $\begin{array}{l}\text { \% within } \\
\text { Group }\end{array}$ & $91.3 \%$ & $82.5 \%$ & $86.9 \%$ & $82.5 \%$ & $62.5 \%$ & $72.5 \%$ & $91.3 \%$ & $62.5 \%$ & $76.9 \%$ \\
\hline & \multirow[b]{2}{*}{ Yes } & Count & 7 & 14 & 21 & 14 & 30 & 44 & 7 & 30 & 37 \\
\hline & & $\begin{array}{l}\% \text { within } \\
\text { Group }\end{array}$ & $8.8 \%$ & $17.5 \%$ & $13.1 \%$ & $17.5 \%$ & $37,5 \%$ & $27.5 \%$ & $8.8 \%$ & $37.5 \%$ & $23.1 \%$ \\
\hline \multicolumn{3}{|c|}{$\mathrm{p}$ value } & \multicolumn{3}{|c|}{0.101} & \multicolumn{3}{|c|}{0.005} & \multicolumn{3}{|c|}{0.0001} \\
\hline
\end{tabular}


There was a significant difference between level of serum $\mathrm{MgSO} 4$ in the three groups after either administration of loading dose of MgSO4 only or administration of loading dose with maintenance dose for 12 hours or 24 hours in the studied patients as mean value of serum $\mathrm{MgSO} 4$ in Group A was; 3.785 $\mathrm{mg} / \mathrm{dl}$, SD 1.0528 (range; 0.9-6.1), Mean value of serum $\mathrm{MgSO} 4$ in Group B was; $4.881 \mathrm{mg} / \mathrm{dl}$, SD 0.9783 (range; 1.9-8), Mean value of serum MgSO4 in Group C was; $5.851 \mathrm{mg} / \mathrm{dl}$, SD 0.9200 (range; 3.08) (Table 5).

Table (4): Comparison between levels of serum MgSO4 in the studied population after administration of MgSQ4

\begin{tabular}{|c|c|c|c|c|c|}
\hline \multicolumn{2}{|c|}{\begin{tabular}{|l} 
Groups \\
Parameters
\end{tabular}} & Group A & Group B & Group C & Total \\
\hline \multicolumn{2}{|l|}{ Mean } & 3.785 & 4.881 & 5.851 & 4.839 \\
\hline \multicolumn{2}{|l|}{$\mathrm{N}$} & 80 & 80 & 80 & 240 \\
\hline \multicolumn{2}{|c|}{ Std. Deviation } & 1.0528 & 0.9783 & 0.9200 & 1.2953 \\
\hline \multicolumn{2}{|c|}{ Minimum } & 0.9 & 1.9 & 3.0 & 0.9 \\
\hline \multicolumn{2}{|c|}{ Maximum } & 6.1 & 8.0 & 8.0 & 8.0 \\
\hline \multicolumn{2}{|l|}{ Median } & 3.800 & 5.000 & 5.800 & 5.000 \\
\hline \multirow{2}{*}{$\begin{array}{c}(\mathrm{t}) \\
\text { Group }\end{array}$} & \multirow{2}{*}{$\begin{array}{c}(\mathrm{J}) \\
\text { Group }\end{array}$} & $\begin{array}{c}\text { Mean } \\
\text { Difference }\end{array}$ & \multirow[t]{2}{*}{ Std. Error } & \multirow[t]{2}{*}{ p value } & $\begin{array}{l}\text { 95\% Confidence } \\
\text { Interval }\end{array}$ \\
\hline & & $(\mathrm{I}-\mathrm{J})$ & & & Upper Bound \\
\hline
\end{tabular}

There was no significant difference between perinatal mortality in the outcome of pregnancy and neonatal ICU admission for the outcome of pregnancy in the three groups after either

Table (5): Comparison between perinatal fetus mortality, prematurity, NICU in the MgSO4

\begin{tabular}{|c|c|c|c|c|c|c|}
\hline \multicolumn{2}{|c|}{$\begin{array}{ll}\text { Parameters } & \text { Groups } \\
\end{array}$} & & $\mathbf{A}$ & B & $\mathbf{C}$ & Total \\
\hline \multirow{6}{*}{$\begin{array}{l}\text { Perinatal } \\
\text { death }\end{array}$} & \multirow{2}{*}{ IUFD } & Count & 4 & 3 & 9 & 16 \\
\hline & & $\%$ within Group & $5.0 \%$ & $3.8 \%$ & $11.3 \%$ & $6.7 \%$ \\
\hline & \multirow{2}{*}{$\begin{array}{l}\text { Neonatal } \\
\text { mortality }\end{array}$} & Count & 3 & 4 & 4 & 11 \\
\hline & & $\%$ within Group & $3.8 \%$ & $5.0 \%$ & $5.0 \%$ & $4.6 \%$ \\
\hline & \multirow{2}{*}{ no } & Count & 73 & 73 & 67 & 213 \\
\hline & & $\%$ within Group & $91.3 \%$ & $91.3 \%$ & $83.8 \%$ & $88.8 \%$ \\
\hline \multirow{2}{*}{\multicolumn{2}{|c|}{ Total }} & Count & 80 & 80 & 80 & 240 \\
\hline & & $\%$ within Group & $100.0 \%$ & $100.0 \%$ & $100.0 \%$ & $100.0 \%$ \\
\hline \multirow[t]{4}{*}{ Prematurity } & No & Count & 41 & 47 & 40 & 128 \\
\hline & & $\%$ within Group & $53.9 \%$ & $61.0 \%$ & $56.3 \%$ & $57.1 \%$ \\
\hline & Yes & Count & 35 & 30 & 31 & 96 \\
\hline & & $\%$ within Group & $46.1 \%$ & $39.0 \%$ & $43.7 \%$ & $42.9 \%$ \\
\hline \multirow{2}{*}{ Total } & & Count & 76 & 77 & 71 & 224 \\
\hline & & $\%$ within Group & $100.0 \%$ & $100.0 \%$ & $100.0 \%$ & $100.0 \%$ \\
\hline \multirow[t]{5}{*}{ NICU } & No & Count & 62 & 65 & 62 & 189 \\
\hline & & $\%$ within Group & $81.6 \%$ & $84.4 \%$ & $87.3 \%$ & $84.4 \%$ \\
\hline & Yes & Count & 14 & 12 & 9 & 35 \\
\hline & & $\%$ within Group & $18.4 \%$ & $15.6 \%$ & $12.7 \%$ & $15.6 \%$ \\
\hline & & Count & 76 & 77 & 71 & 224 \\
\hline \multicolumn{2}{|l|}{ Total } & $\%$ within Group & $100.0 \%$ & $100.0 \%$ & $100.0 \%$ & $100.0 \%$ \\
\hline
\end{tabular}

administration of loading dose of $\mathrm{MgSO} 4$ only or administration of loading dose with maintenance dose for 12 hours or 24 hours in the studied patients (Table 6).

\section{outcome of pregnancy in the studied groups after administration of}




\section{DISCUSSION}

Preeclampsia is a major cause of perinatal and maternal morbidity and mortality, which affects 2-5\% of pregnancies (Ngwenya et al., 2017).

Management of pre-eclampsia is based on stabilization, continued monitoring and delivery at an optimal time for mother and her baby. There is strong evidence from many randomized trials that supports the use of magnesium sulfate for the prevention and treatment of women with eclampsia (Berhan et al., 2015).

The incidence of seizures in untreated pre-eclamptic women is approximately 3$4 \%$, whilst for those receiving magnesium sulfate; the rate is $0.8-1 \%$ (Duley et al., 2011).

There is a little reliable evidence from randomized trials assessing the minimum effective dose, the comparative effects of alternative routes of administration (intravenous or intramuscular), or the ideal duration of therapy (Duley et al., 2011).

In the present work, there was no significant difference between occurrence of eclampsia, HELLP syndrome, maternal side effects or perinatal mortality and neonatal ICU admission in the three groups after either administration of loading dose of $\mathrm{MgSO} 4$ only or administration of loading dose with maintenance dose for 12 hours or 24 hours in the studied patients However, there was a significant difference between maternal ICU admissions in the three groups with highest rate in Group $\mathrm{C}$ and lowest rate in Group A. Also, there was a significant difference between levels of serum $\mathrm{MgSO} 4$ in the three groups.

Our study compared that three different regimens for administration of $\mathrm{MgSO} 4$ (loading dose only, abbreviated regimen with maintenance sulfate for only 12 hours and standard regimen with maintenance dose for 24 hours) in management of severe preeclampsia.

Tabassum et al. (2009) found that there was no significant difference in the two groups in term of occurrence of seizures .In our study we include patients with severe preeclampsia not mild and we consider loading dose only as a comparative regimen. Maia et al. (2014) found that none of these women and none of the other cohort given the 24 hour magnesium infusion developed eclampsia. Other studies were conducted on women with eclampsia comparing the loading dose versus the standard regimen for MgSO4 with similar outcome. Barber et al. (2009) found that only loading dose of MgSO4 can control convulsion in eclampsia and it is as effective as standard regimen. Calvin et al (2013) found that the shortened postpartum course of magnesium sulfate is as effective as the standard Pritchard regimen in the management of eclampsia. Regmi et al. (2010) found that loading dose of magnesium sulfate is a good alternative for standard Pritchard regimen. It avoids multiple painful injections of magnesium Sulfate.

Bhattacharjec et al. (2011) found that low-dose intravenous magnesium sulfate was found to be as effective as the standard intramuscular regimen, while maintaining a high safety margin. 


\section{CONCLUSION}

The early diagnosis of severe preeclampsia is very important in order to minimize maternal and fetal complications. We Magnesium sulfate proved to cause many hemodynamic changes as it has vasodilator effect on maternal and fetal blood vessels However; magnesium sulfate should be given to all patients with severe preeclampsia. Considering the equal effectiveness, fewer side effects, ease of monitoring and costeffectiveness of loading dose, single loading dose of magnesium sulfate in the management of pre-eclampsia is preferable to other regimes of administration requiring multiple doses.

\section{REFERENCES}

1. Al-Jameil, N., Khan, F. A., Khan, M. F and Tabassum, H. (2014): A brief overview of preeclampsia. Journal of Clinical Medicine Research,; 6(1):9- 16.

2. Barber D, Xing $G$ and Towner D (2009): Expectant management of severe eclampsia between 24-32 weeks gestation: A ten year review. Abstract No 742. Presented at the 29th Annual Meeting of the Society for Maternal-Fetal Medicine,; 26-31.

3. Berhan, $Y$ and Berhan, A (2015): Should magnesium sulfate be administered to women with mild pre-eclampsia? A systematic review of published reports on eclampsia. Journal of Obstetrics and Gynaecology Research; 41(6), 831-842.

4. Bhattacharjee, N. (2011): A randomised comparative study between low-dose intravenous magnesium sulphate and standard intramuscular regimen fortreatment of eclampsia. Journal of Obstetrics and Gynaecology Research: 41(6), 831-842.

5. Calvin M. (2014): A Shortened versus Standard Matched Postpartum Magnesium Sulphate Regimen in the Treatment of Eclampsia: a Randomised Controlled trial.
African Journal of Reproductive Health 17(3): 136.

6. Cui, Y., Wang, W., Dong, N., Lou, J., Srinivasan, D. K., Cheng, W. and Chen, S. (2012): Role of corin in trophoblast invasion and uterine spiral artery remodelling in pregnancy. Nature, 484(7393): 246-250.

7. Dhakal G, Subedi M and Paudel K. (2012): Magnesium sulphate in management of severe pre-eclampsia and eclampsia. J Nepal Health Res Counc.; 10(21):1 13-7.

8. Duley, L., Henderson-Smart, D. J., and Chou, D. (2010): Magnesium sulphate versus phenytoin for eclampsia. Cochrane Database of Systematic Reviews. (10).

9. Greenberg, M. B., Penn, A. A., Whitaker, K. R., Kogut, E. A., El-Sayed, Y. Y., Caughey, A. B., and Lyell, D. J. (2013): Effect of magnesium sulfate exposure on term neonates. Journal of Perinatology: 33(3), 188-193.

10. Maia, S. B., Katz, L., Neto, C. N., Caiado, B. V., Azevedo, A. P. and Amorim, M. M. (2014): Abbreviated (12-hour) versus traditional (24-hour) postpartum magnesium sulfate therapy in severe pre-eclampsia. International Journal of Gynecology \& Obstetrics: 126(3), 260-264.

11. Ngwenya, S (2017): Severe preeclampsia and eclampsia: incidence, complications, and perinatal outcomes at a low-resource setting, Mpilo Central Hospital, Bulawayo, Zimbabwe. International journal of women's health,; 9: 353.-362

12. Regmi MC, Aggrawal A, Pradhan T, Rijal P, Subedi A and Uprety D (2010): Loading dose versus standard regimen of magnesium sulphate in eclampsia - a randomized trial. Nepal Med Coll J, 12(4): 244-247.

13. Tabassum ,S , Saba ,K, Iffat, $J$ and Shereen Z. and Bhutta, D (2009): Loading Dose of Magnesium Sulphate Versus Standard Regime for Prophylaxis of Preeclampsia. Journal of the College of Physicians and Surgeons Pakistan, 19 (1): 3033.

14. Uzan, J., Carbonnel, M., Piconne, O., Asmar, R. and Ayoubi, J. M. (2011): Pre- 
eclampsia:pathophysiology, diagnosis, and management. Vascular health and risk management, 7, 467-476
15. Young, B. C., Levine, R. J., and Karumanchi, S. A. (2010): Pathogenesis of preeclampsia. Annual Review of Pathology: Mechanisms of Disease, 5:173-192. 


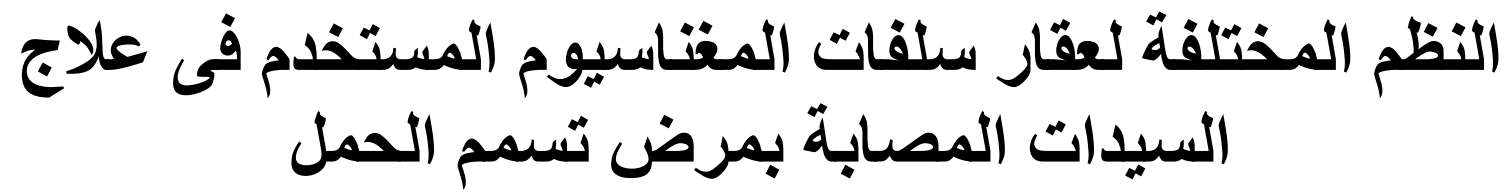

يحى وفا، محمد المهندس، مصطقى هيكل

قسم التوليا وأمراض النساء، كلية الطب، جامعة الأزهر

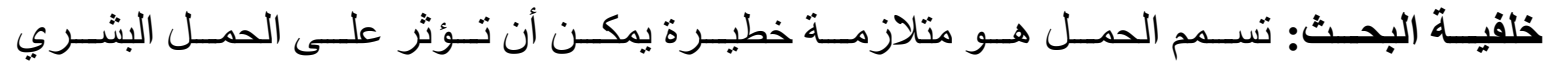

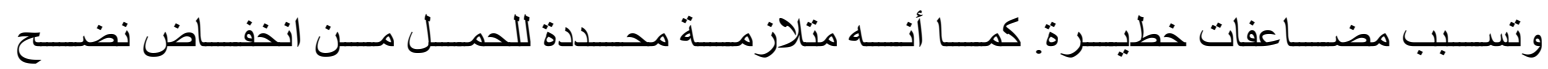
الجهاز الثانوي لنتنج الأوعية وتنشيط البطانية.

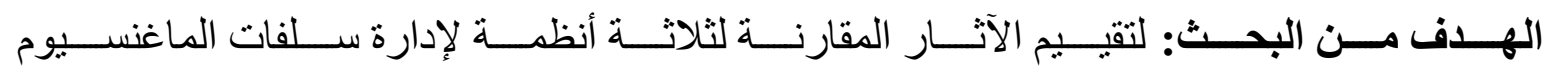

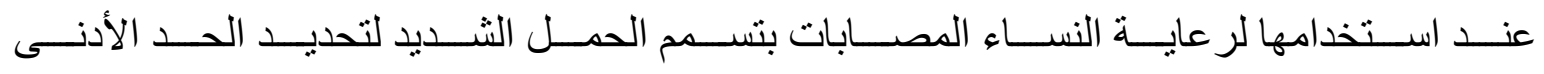

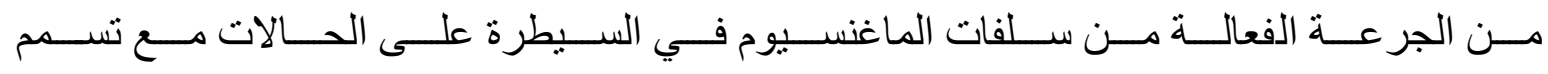

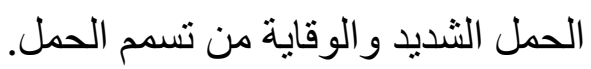

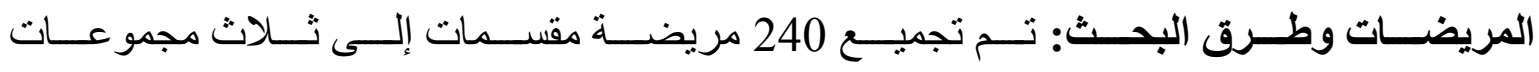

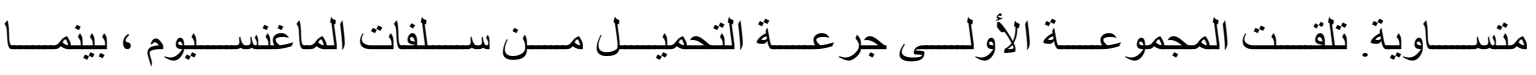

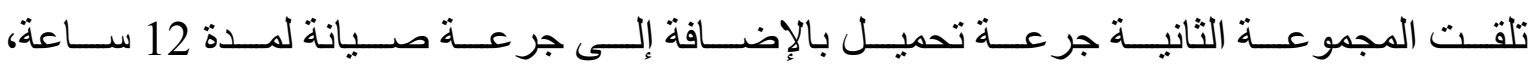

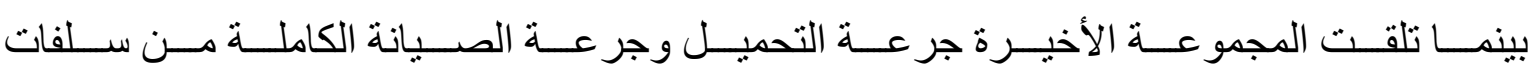
الماغنسيو لمدة 24 ساعة.

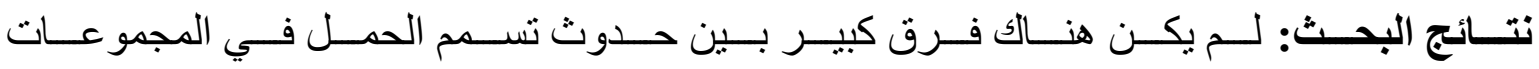
الثلاث اللاتى شملتهن الدراسة.

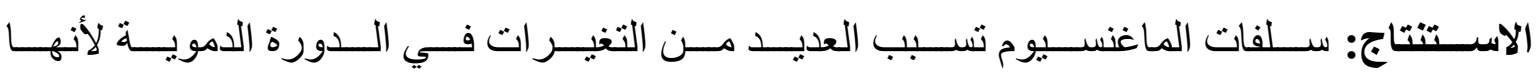

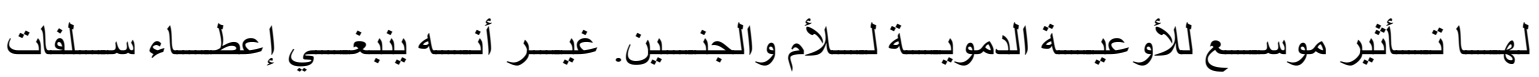
الماغنسيوم لجميع المرضى الذين يعانون من تسمم الحمل الثنديد. 